associated with a small V.S.D. in childhood tends to rise in later life. ${ }^{22}$ The risk of infective endocarditis has often been listed as a reason for surgical closure of small defects, but this is now agreed to be small. ${ }^{23}$ So to summarize it may be stated that the natural history of ventricular septal defect with low pulmonary artery pressure is benign. Heart failure in infancy does not necessarily lead to death or to later inoperability but if either of these possibilities seems likely then primary closure of the defect in infancy should be preferred to banding, provided the services of a first-class centre are available. After infancy the presence of pulmonary hypertension is the key to prognosis, and surgical closure is likely to modify this favourably provided pulmonary vascular obstruction is not too far advanced.

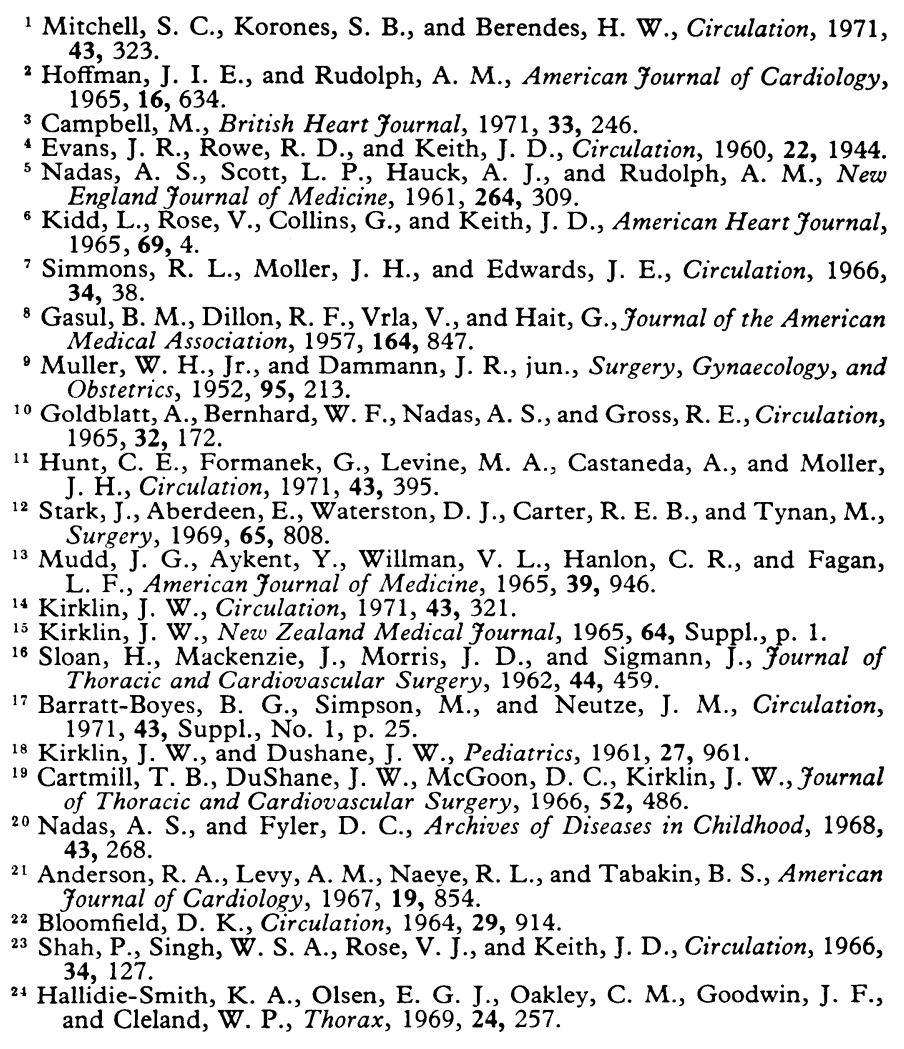

\section{Clinical Tutors and Medical Centres}

The formation in 1970 of the National Association of Clinical Tutors emphasized how greatly postgraduate medical education has developed in Britain in recent years. From a position where postgraduate medical education and training were haphazard and poorly integrated there has emerged a situation in which opportunities for keeping abreast with new advances and the best current practice are probably second to none in the world. Major factors in this change of scene have been the formation of medical teaching centres in regional hospitals; an administrative structure for postgraduate education based on universities, with medical schools working closely with regional hospital boards; and the appointment of clinical tutors.

The shortage of postgraduate facilities, underlined after the second world war by the number of demobilized Service medical officers needing further training and later by the influx of doctors from overseas seeking specialist diplomas, was first met by individual initiative, using funds collected from local private sources (including members of the medical profession and from industry), and by generous grants from charitable trusts. The Association for the Study of Medical Education was formed in 1957, and it added to the mounting pressure to put the postgraduate educational house in order.

After a conference in 1961, called by the Nuffield Provincial Hospitals Trust, ${ }^{1}$ of those interested in promoting postgraduate medical education the Trustees set aside $£ 250,000$ to finance regional and area schemes for postgraduate training in the provinces. The King Edward Hospital Fund provided a similar sum for use in the Metropolitan regions. The Ministry of Health, to its great credit, encouraged the movement in 1964 by providing for the appointment of clinical tutors by universities after consultation with regional hospital boards and local consultants and for a small honorarium to be paid. The Ministry also emphasized the need to provide physical facilities for teaching in regional hospitals available to doctors in all branches of medicine, and the crucial guiding and controlling role of the universities working in conjunction with regional boards was acknowledged. The Todd report in $1968^{2}$ recommended an extension of these developments, and the Department of Health and Social Security is now providing more money for the furtherance of postgraduate medical education.

Unfortunately, money available from public sources is often insufficient to meet the demands upon it, and help from other quarters is still often necessary. A potential source of help is the pharmaceutical industry, but the type of publicity a firm might expect in return may lead to difficulty. One of the topics discussed at last week's meeting of the tutors' association (see p. 634) was the relationship of pharmaceutical firms to medical centres. Certain guidelines have been put forward by the Department of Health which, on the whole, met with approval. It would certainly seem to be essential that all activities in medical centres involving or helped by pharmaceutical firms should be controlled by the clinical tutor, who must retain complete academic freedom in arranging programmes and selecting speakers-however critical they may be of any product marketed by the sponsoring firm.

The task of postgraduate medical education, consisting as it does of vocational training for all the specialties, together with the continuing education so essential to enable all doctors to keep reasonably abreast of the rapid advances in their subject, is quantitatively much greater than that of undergraduate education. This requires the work to be widely spread, and its effect on the more senior members of the profession who have to participate is generally regarded as stimulating.

The first medical centre was conceived at Stoke-on-Trent in 1959 and came into use in 1964. The National Association of Clinical Tutors, in conjunction with the Council for Postgraduate Medical Education in England and Wales and with help from the Nuffield Provincial Hospital Trust, is now producing a directory of medical centres. Their number at present is uncertain. From the most recent count ${ }^{3}$ there are probably about 300 clinical tutors in the United Kingdom, and would be only slightly fewer centres, for it is now accepted that no district general hospital is complete without one. They serve as a meeting place for hospital staff, general practitioners, and medical officers of health, thus they are an important means of bringing together the three branches of the Health Service. Apart from the clinical demonstrations, clinicopathological conferences, and 
"grand rounds" mainly for hospital staff, there are courses, conferences, and lectures concerning topics of community and family medicine. A library is open to all doctors in the locality, and in many there are a variety of audiovisual aids and study rooms. Catering and bar facilities enhance the club atmosphere, and lunch-time sessions are useful to busy general practitioners.

If continuing education is now well catered for vocational training is not so as yet. But suitable schemes such as those associated with day-release are being evolved and put into effect. One of the difficulties highlighted at the association's meeting was how to reconcile the calls of good vocational training with service needs. There was a division of opinion among tutors about the role of the universities, some suggesting that they contributed little and had no place to play in the postgraduate educational field. Others, however, had obtained considerable help from their university connections and it seemed that these opinions reflected the differing conditions from region to region. It is reasonably certain that the university/regional hospital board symbiosis envisaged by the Ministry of Health in 1964 will be more fruitful than either body alone, and any variations encountered are likely to result from the personalities involved rather than from the system. The centres which grew up as an essential instrument of continuing medical education will become equally essential for proper vocational training. It is important therefore that the centres-though their facilities may be made available to groups allied to medicine-should keep their own identity as educational and academic centres for doctors and that they should continue to be controlled by the clinical tutor. The great expansion in teaching is throwing a strain on many who are called upon to prepare and deliver lectures or to help in some other formal way, and this should be provided for by allowing for teaching sessions in their contracts. The momentum which has been gained must not be lost before the goals have been reached.

${ }_{1}^{1}$ British Medical Fournal, 1962, 1, 466

2 Report of the Royal Commission on Medical Education, 1965-8. London, H.M.S.O., 1968.

${ }^{3}$ Lister, J., unpublished data.

\section{Spontaneous Pneumothorax and Apical Lung Disease}

Though spontaneous pneumothorax can occur at any age and result from a variety of chronic lung diseases, it most often afflicts young men with good previous health and normal chest radiographs. ${ }^{1}$ In this group of patients the aetiology is obscure, though thoracotomy will often disclose a ruptured subpleural emphysematous bulla. ${ }^{2}$

I. Lichter and J. F. Gwynne ${ }^{3}$ have recently described the pathological findings in 20 such patients who came to thoracotomy because the pneumothorax was either persistent or recurrent. In every case a lesion was found in the apex of the upper lobe, and in most of them the remainder of the lung seemed healthy. The lesion was usually less than 2 or 3 $\mathrm{cm}$ in diameter and consisted of an area of fibrosis and collapse surmounted by one or more thin-walled air cysts. Microscopy showed inflammatory changes which were attributed to non-specific infection.

This apical localization of the causative lesion may be relevant to the pathogenesis of "idiopathic" pneumothorax.
There are several factors which could determine whether a disease process affects chiefly the upper or the lower parts of the lung. For example, ventilation and perfusion are preferentially distributed to the lung bases in the upright posture, and this may account for the predominant involvement of the lower lung in smoker's bronchitis and in emphysema associated with $\alpha_{1}$ anti-trypsin deficiency. ${ }^{4}$ The extreme lung apex receives some ventilation but no perfusion and thus provides an oxygen-rich but ischaemic environment, which is said to favour the proliferation of certain organisms, notably the tubercle bacillus. ${ }^{5}$

Not only ventilation and perfusion but also inflationary stresses are unevenly distributed between the upper and lower parts of the lung. ${ }^{6}$ Distortion of the upright lung by its own weight causes higher negative intrapleural pressures ${ }^{7}$ and more fully distended alveoli 89 at the apex than at the base. These circumstances should favour the development, expansion, and rupture of abnormal air spaces in the upper lobes and may thus explain the predilection for this site of centrilobular $^{10}$ and non-bronchitic bullous ${ }^{11}$ emphysema, tuberculous cavitation, and the causative lesion in idiopathic pneumothorax. ${ }^{3}$

Distortion by gravity should be greater in lungs with a large vertical height, and so this mechanical hypothesis receives some support from the observation that young men with pneumothorax tend to be above average height ${ }^{312} 13$ and that, in one reported series, ${ }^{11}$ patients with apical bullous emphysema were on average 3 in $(8 \mathrm{~cm})$ taller than those with bronchitis and predominantly basal disease. The intractable cavitation which may complicate apical fibrosis in patients with ankylosing spondylitis ${ }^{14}$ could be explained on a similar mechanical basis. Ankylosis of the costovertebral joints impedes expansion of the lung, and since the deflated lung is also more flaccid it is more readily distorted by its own weight. ${ }^{6}$ The increased vertical action of the diaphragm in these cases would further add to the stresses on the lung apex.

To return to the problem of pneumothorax in young men: it may be that relative ischaemia of the lung apex makes this part more susceptible to infective lesions of various kinds; the subsequent expansion and rupture of a bulla accompanying such a lesion may then be determined by gravitational stresses. This apical localization of the disease process in idiopathic pneumothorax certainly justifies the view expressed by Lichter and Gwynne ${ }^{3}$ that wedge resection is a more rational treatment than the instillation of pleural irritants.

If gravity is indeed a cause of some apical forms of emphysema, cavitation, and pneumothorax, these conditions could now be listed with inguinal hernia and uterine prolapse as the penalties for man's assumption of the erect posture.

British Medical fournal, 1968, 1, 720

Killen, D. A., and Gobbell, W. G., Spontaneous Pneumothorax, Boston, Little, Brown, 1968.

${ }^{3}$ Lichter, I., and Gwynne, J. F., Thorax, 1971, 26, 409

4 British Medical fournal, 1971, 3, 655.

5 Riley, R. L., Bulletin of the fohns Hopkins Hospital, 1960, 106, 232.

6 Riley, R. L., Bulletin of the fohns

7 Krueger, J. J., Bain, T., and Patterson, J. L., fournal of Applied Physiology, $1961,16,465$.

${ }^{8}$ Milic-Emili, J., Henderson, J. A. M., Dolovich, M. B., Trop, D., and Kaneko, K., Fournal of Applied Physiology, 1966, 21, 749.

${ }^{9}$ Glazier, J. B., Hughes, J. M. B., Maloney, J. E., and West, J. B., fournal of Applied Physiology, 1967, 23, 694.

10 Thurlbeck, W. M., American Review of Respiratory Diseases, 1963, 87, 206.

11 Ogilvie, C., and Catterall, M., Thorax, 1959, 14, 216.

12 Withers, J. N., Fishback, M. E., Kiehl, P. V., and Hannon, J. L., 1964, American fournal of Surgery, 108, 772.

13 Forgacs, P., Thorax, 1967, 22, 481.

14 British Medical fournal, 1971, 3, 492. 